\title{
Tobacco use and associated factors among school students in Dubai, 2010: intervention study
}

\author{
H.A. Obaid, ${ }^{7}$ M.A. Hassan, ${ }^{7}$ N.H. Mahdy, ${ }^{7}$ M.I. ElDisouky, ${ }^{1}$ F.E. Alzarba, ${ }^{1}$ S.R. Alnayeemi, ${ }^{1}$ M.C. Rillera ${ }^{7}$ and B.S. AlMazrooei ${ }^{7}$
}

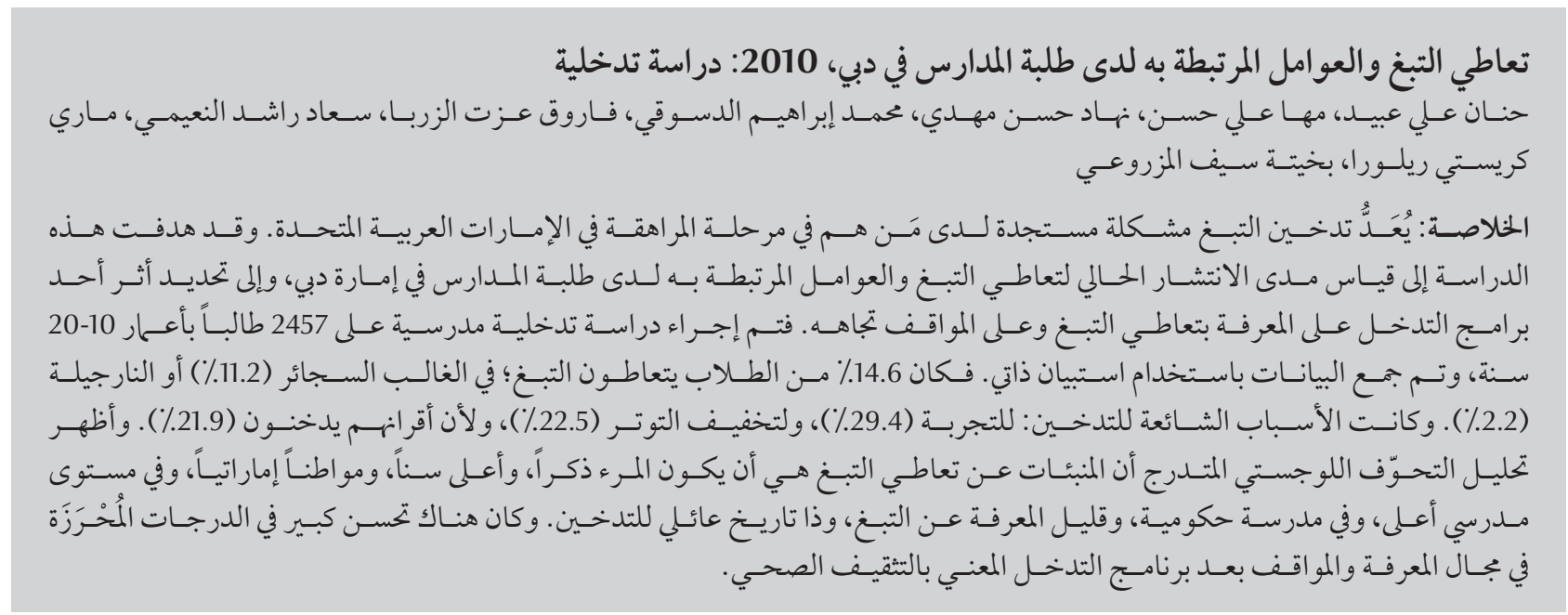

ABSTRACT Tobacco smoking is an emerging problem among adolescents in the United Arab Emirates (UAE). This study aimed to measure the prevalence of current tobacco use and its associated factors among school students in Dubai Emirate and to determine the impact of an intervention programme on knowledge and attitudes towards tobacco use. A school-based intervention programme was carried out among 2457 students aged 10-20 years and data were collected with a self-administered questionnaire. Of the students, $14.6 \%$ were tobacco users, mostly cigarettes (11.2\%) and waterpipes (2.2\%). The most common self-reported reasons for smoking were for the experience (29.4\%), for stress relief (22.5\%) and because their peers smoked (21.9\%). Stepwise logistic regression analysis showed that the predictors of tobacco use were: male, higher age, UAE national, higher school level, government school, low knowledge about tobacco and family history of smoking. There were significant improvements in knowledge and attitudes scores after the health education intervention programme.

Tabagisme et facteurs associés chez des élèves à Dubaï, 2010 : étude d'intervention

RÉSUMÉ Le tabagisme chez les adolescents aux Émirats arabes unis représente un problème récent. La présente étude visait à mesurer la prévalence actuelle du tabagisme et les facteurs associés chez des élèves dans l'Émirat de Dubaï. Elle avait également pour objectif de déterminer l'impact d'un programme d'interventions sur leurs connaissances et attitudes à l'égard du tabagisme. Un programme d'interventions a été mené en milieu scolaire auprès de 2457 élèves âgés de 10 à 20 ans. Les données ont été recueillies à l'aide d'un questionnaire auto-administré. Parmi les élèves interrogés, 14,6 \% étaient des consommateurs de tabac, principalement de cigarettes $(11,2 \%)$ ou de pipes à eau (2,2\%). Les raisons les plus fréquentes motivant la consommation de tabac étaient le fait d'expérimenter (29,4\%), I'atténuation du stress $(22,5 \%)$ et la consommation de tabac par les pairs (21,9\%). L'analyse de régression logistique par étapes a démontré que les facteurs prédictifs du tabagisme étaient les suivants : être de sexe masculin, être plus âgé, avoir la nationalité émirienne, avoir un niveau scolaire plus élevé, fréquenter une école publique, avoir de faibles connaissances sur le tabac et venir d'une famille de fumeurs. Des améliorations notables ont été constatées dans les scores sur les connaissances et les attitudes après la mise en oeuvre du programme d'interventions d'éducation pour la santé. 


\section{Introduction}

Tobacco use is one of the biggest public health threats the world has ever faced (1). Tragically, the epidemic is shifting towards the developing world, where $80 \%$ of tobacco-related deaths will occur within a few decades. Tobacco has killed more than 100 million people in the 20th century and it is expected to kill billions in the 21st century. The shift has been attributed to a global tobacco industry marketing strategy that targets young people and adults in developing countries (1).

Adolescence is a period of physical, cognitive and emotional change and of searching for a personal identity that frequently involves experimentation with various risky behaviours including smoking (2). In most countries, the great majority of smokers begin to use tobacco before the age of 18 years $(3,4)$. Adolescents who start smoking at an early age seem to be at much greater risk of the adverse health consequences of smoking than late starters. Also, nicotine addiction among these early smokers appears more severe than that among late starters (5). Saudi Arabia has reported a high prevalence of current smoking (29.8\%) among schoolboys and found that $83.7 \%$ of them started smoking at or before the age of 15 years (6). The Global Youth Tobacco Survey in Egypt in 2005 reported that 13.6\% of students had ever smoked cigarettes and $14.4 \%$ currently use any tobacco product (7). According to the Global School-based Student Health Survey in the United Arab Emirates (UAE), conducted in $2005,12.7 \%$ of students had used any tobacco on 1 or more days during the past 30 days and about $9.3 \%$ of students had smoked cigarettes (8).

It has been reported that the main reasons why adolescents start smoking are emulation, curiosity, friendship effect, stress, "proving themselves" to peers and the presence of a family member who smokes (9). Knowledge and attitudes about smoking are significantly associated with smoking. It was reported that a high prevalence of smoking was associated with poor knowledge about smoking and a low attitude score (10). Tobacco control legalization in the UAE started after the launch of an anti-tobacco federal law in 2009, which applied a smoking ban in all public premises including schools and universities (11). The legislation makes it illegal to sell cigarettes to anyone under 18 years or to smoke in cars carrying children under 12 years old (12).

The increasing magnitude of the tobacco smoking habit among adolescents in the UAE is an emerging problem that needs to be thoroughly studied in order to plan for proper control measures and to develop effective policies for smoking prevention and cessation programmes. The objectives of the current study were 2 -fold: to measure the prevalence of current tobacco use (smoked and smokeless tobacco products) among school students in Dubai and the factors associated with tobacco use; and to determine the impact of a health education intervention programme on knowledge and attitude of students towards tobacco use and its hazards.

\section{Methods}

\section{Study design and setting}

A school-based intervention study (quasi-experimental) was carried out in preparatory and secondary schools in Dubai. The target population was male and female school students in school grades 7 to 12 .

\section{Sampling}

The sample size was calculated using the computer program Epi-info, version 6.04. The total number of preparatory- and secondary-school students in Dubai was 77 118, and using 2\% degree of precision, estimated prevalence of tobacco use among adolescents of 19.5\% (from a previous, similar study in UAE) (8), 1.5 design effect and 95\% confidence interval the minimum sample size required was 2219 .

Stratified random sampling with proportional allocation was carried out. Stratification was based on the administrative regions of Dubai (Deira or Bur Dubai), sex (male or female), type of school (government or private) and school grade (preparatory or secondary). Overall, in both Deira and Bur Dubai the total number of private schools exceeded the number of government schools by 3 to 1 . Thus 24 private schools and 8 government schools were randomly selected from both regions. For the private schools 12 schools were selected randomly from each region ( 6 for males and 6 for females) and for the government schools 4 schools were selected randomly from each region (2 for males and 2 for females). One class was selected randomly from each of selected preparatory (grades 7-9) and secondary (grades 10-12) schools and all the students in the selected classes were invited to participate in the survey.

The total sample size amounted to 2457. All selected schools as well as all the students within the selected schools agreed to participate in the study (response rate 100\%).

\section{Data collection}

\section{Questionnaire}

The data were collected from students using an anonymous, self-administered, pre-coded questionnaire. It consisted of 32 questions. Filling the questionnaire took approximately $10 \mathrm{~min}$. Students were assured that the information they provided would remain confidential and thus were encouraged to be truthful in their responses. They were informed that their participation was completely voluntary. The questionnaire was distributed in English for private-school students (1976 students) and in Arabic for government-school students (481 students). The questionnaire was originally designed in English then 
back-translated into Arabic and reviewed by a community professional.

The questionnaire collected the following information from the participants: sociodemographic characteristics such as type of school, age, sex, nationality (local, i.e. UAE nationality, or non-local, i.e. non-UAE nationality), grade of education and parents' education; family history of smoking; knowledge about tobacco use and the health risks of using it; and attitudes to smoking.

The knowledge questions were adopted from the Global Youth Tobacco Survey and other studies that revealed satisfactory reliability (Cronbach $\alpha$ around 0.84$)(13,14)$. The students were asked if they thought that tobacco use was harmful to health and that smoking tobacco can be addictive like heroin. It also included questions regarding other hazards of smoking such as cancer, cardiovascular diseases and respiratory tract diseases. In addition, they were asked if using tobacco was bad only if it was used for many years and whether smoking in close public places can be harmful to nonsmokers. Each item had a choices of 3 answers (no, yes or don't know) and a score of 0 was given for the incorrect answer or don't know and score of 1 for the correct answer, giving a score range for the knowledge scale of $0-7$. The scores were summed and students were categorized into 3 groups: poor knowledge (score $<50 \%$ ), fair knowledge (score 50-74\%) and good knowledge (score $\geq 75 \%$ ).

The questions to assess the attitude of students toward tobacco use were adopted from the Global Youth Tobacco Survey and other studies that revealed satisfactory reliability (Cronbach $a$ around 0.82) (13-15). Students were asked if they thought that tobacco use was a bad habit, made them relax and cope with stress, made them more attractive, made them less healthy, led to bad smells and affected their performance in sports. They were also asked if they believed that tobacco must be banned in closed places or not and whether parents should not allow their children to use tobacco or not. Each item had 3 choices (agree, not sure or disagree) and a score of 1 was given for negative attitude, 2 for neutral and 3 for positive attitude, giving a score rage for the attitude scale of 11-33. The total scores were calculated and the students were classified into 3 groups: negative attitude (i.e. favourable towards smoking) (score $<50 \%$ ), neutral attitude (score 50-< $74 \%$ ) and positive attitude (i.e. unfavourable towards smoking) (score $\geq$ $75 \%)$

Data about tobacco use included questions about tobacco product use (cigarettes, waterpipes, pipes, cigars and chewing tobacco) during the 30 days preceding the survey. Questions were asked about the age at which tobacco use was initiated, duration of use as well as students' self-reported reasons for use, such as peer pressure, selfachievement, parents' smoking, stress reduction, social problems or simply to imitate adults. In addition, we asked about exposure to other people's smoking (second-hand smoke exposure) and their desire to quit tobacco use.

\section{Operational definition}

World Health Organization (WHO) definitions were used which define the prevalence of current tobacco use among youth as the prevalence of tobacco use (including smoking cigarettes, pipes, cigars, waterpipes and oral tobacco) on more than 1 occasion in the 30 days preceding the survey, regardless of amount used (11).

\section{Intervention - health education programme}

The health education programme was conducted in the 1 academic year 2009-2010 and targeted all the selected schools. During this period the selected schools chose a date for the allocated class to conduct the pre-test questionnaire followed immediately by a 1-day intervention programme, then after an interval of 2 weeks the second date was allocated for the same class to complete the post-test questionnaire. The intervention programme consisted of a health education session that discussed the hazards of smoking. This was conducted through lecture presentations and video shows on the hazards of use of various tobacco products. Educational materials about the hazards of tobacco use were distributed. The programme was conducted by a professional team of physicians trained in this field.

\section{Ethical considerations}

An approval was obtained from the Dubai Knowledge and Human Development and Dubai Health Authority after explaining the purpose of the study. Approval was also taken from all participating schools and it was made clear to students that participation was completely voluntary. Absolute confidentiality of the data was maintained throughout the study.

\section{Statistical analysis}

The data were analysed using SPSS software program, version 19.0. The following statistical analyses were performed. The data were presented by frequency tables and graphs. Descriptive statistics were presented for quantitative variables [mean, standard deviation (SD) and range]. The chisquared test was used for testing the relationship between sociodemographic factors, knowledge, attitude and tobacco use. The paired t-test was used for comparing the mean scores before and after the intervention programme in both the knowledge and attitude domains. $P<0.05$ was the cut-off level of significance.

Stepwise logistic regression was carried out to adjust the confounders and delineate the predictors for tobacco use. The dependent factor was any tobacco use $(0=$ no, $1=$ yes $)$. The independent factors were: age (continuous variable), 
$\operatorname{sex}(0=$ female, $1=$ male $)$, nationality ( 0 = non-local, $1=$ local), type of school ( 0 = government, 1 = private $)$, school grade $(0=$ preparatory grades $7-9,1=$ secondary grades $10-12)$, parental education ( 0 = university level, 1 = secondary $/$ preparatory, 2 = illiterate/primary), family history of smoking $(0=$ no, $1=$ yes), and knowledge scores and attitude scores (continuous variables) towards tobacco use.

\section{Results}

\section{Background characteristics}

The present study included 2457 students, with a mean age of 14.85 (SD 1.67) years, range 10-20 years. Due to the higher number of private schools, the number of non-UAE national students who participated (1545 students) were greater than the UAE national students (912 students). Table 1 shows that $80.4 \%$ of the sample were from private schools, over half were males (54.4\%) and $62.9 \%$ were non-locals. The majority of students' parents had university education or higher $(68.3 \%$ and $76.4 \%$ for mothers and fathers respectively). Among the respondents $29.1 \%$ reported that they were exposed to second-hand smoke at home.

\section{Prevalence of smoking}

Out of 2457 students, there were 359 self-reported tobacco smokers (14.6\%). Cigarette smoking was the most prevalent type of tobacco use (11.2\%), while waterpipes (shisha) were used by only $2.2 \%$, pipes by $1.9 \%$ and cigar and chewing tobacco by $0.8 \%$ each.

\section{Reasons for smoking}

The most common self-reported reasons for smoking were to try out the experience (29.4\%), relieving stress (22.5\%) and peers' smoking (21.9\%). Some students reported that the reasons related to social problems (6.4\%), parents' smoking $(6.0 \%)$ or to improve self-achievement (3.7\%).

\section{Knowledge and attitudes towards tobacco use}

Concerning knowledge and attitudes, it was found that before the intervention programme $35.0 \%$ of the students had a poor level of knowledge about tobacco use and its hazards and $41.3 \%$ demonstrated negative attitudes (i.e. were favourable) towards tobacco use.
Mean knowledge scores were significantly higher among non-tobacco users compared with any tobacco users [5.58 (SD 1.79) versus 5.27 (SD 2.02) respectively] $(P=0.004)$. The same pattern was observed for the mean attitude scores [29.28 (SD 3.29) and 28.68 (SD 3.50) respectively] $(P=0.004)$ (Table 2).

Table 1 Distribution of school students according to demographic characteristics, Dubai 2010

\begin{tabular}{|c|c|c|}
\hline \multirow[t]{2}{*}{ Demographic characteristic } & \multicolumn{2}{|c|}{ Total $(n=2457)$} \\
\hline & No. & $\%$ \\
\hline \multicolumn{3}{|l|}{ Type of school } \\
\hline Government & 481 & 19.6 \\
\hline Private & 1976 & 80.4 \\
\hline \multicolumn{3}{|l|}{ School grade } \\
\hline Preparatory & 1327 & 54.0 \\
\hline Secondary & 1130 & 46.0 \\
\hline \multicolumn{3}{|l|}{ Sex } \\
\hline Male & 1337 & 54.4 \\
\hline Female & 1120 & 45.6 \\
\hline \multicolumn{3}{|l|}{ Age (years) } \\
\hline $10-$ & 34 & 1.5 \\
\hline $12-$ & 539 & 23.0 \\
\hline $14-$ & 889 & 38.0 \\
\hline $16-$ & 784 & 33.5 \\
\hline $18-$ & 93 & 4.0 \\
\hline Mean (SD) & \multicolumn{2}{|c|}{$14.85(1.67)$} \\
\hline \multicolumn{3}{|l|}{ Nationality } \\
\hline Local & 912 & 37.1 \\
\hline Non-local & 1545 & 62.9 \\
\hline \multicolumn{3}{|l|}{ Mother's educational level ${ }^{a}$} \\
\hline Illiterate & 116 & 4.8 \\
\hline Primary & 103 & 4.2 \\
\hline Preparatory & 99 & 4.1 \\
\hline Secondary & 451 & 18.6 \\
\hline University & 1657 & 68.3 \\
\hline \multicolumn{3}{|l|}{ Father's educational level $^{b}$} \\
\hline Illiterate & 79 & 3.3 \\
\hline Primary & 51 & 2.1 \\
\hline Preparatory & 136 & 5.6 \\
\hline Secondary & 307 & 12.6 \\
\hline University & 1857 & 76.4 \\
\hline \multicolumn{3}{|l|}{ History of smoking in the family } \\
\hline No & 1742 & 70.9 \\
\hline Yes & 715 & 29.1 \\
\hline
\end{tabular}

${ }^{a}$ Missing data for 31 students; ${ }^{b}$ Missing data for 27 students. $S D=$ standard deviation. 


\begin{tabular}{|c|c|c|c|c|c|c|}
\hline \multirow[t]{3}{*}{ Variable } & \multirow{3}{*}{$\begin{array}{c}\text { Total } \\
(n=2457) \\
\text { No. }\end{array}$} & \multicolumn{4}{|c|}{ Any tobacco use } & \multirow[t]{3}{*}{$P$-value ${ }^{a}$} \\
\hline & & \multicolumn{2}{|c|}{$\begin{array}{c}\text { No } \\
(n=2098)\end{array}$} & \multicolumn{2}{|c|}{$\begin{array}{c}\text { Yes } \\
(n=359)\end{array}$} & \\
\hline & & No. & $\%$ & No. & $\%$ & \\
\hline \multicolumn{7}{|l|}{ Type of school } \\
\hline Government & 481 & 369 & 76.7 & 112 & 23.3 & \multirow{2}{*}{$<0.001$} \\
\hline Private & 1976 & 1729 & 87.5 & 247 & 12.5 & \\
\hline \multicolumn{7}{|l|}{ School grade } \\
\hline Preparatory & 1327 & 1155 & 87.0 & 172 & 13.0 & \multirow{2}{*}{0.012} \\
\hline Secondary & 1130 & 943 & 83.5 & 187 & 16.5 & \\
\hline \multicolumn{7}{|l|}{ Sex } \\
\hline Male & 1337 & 1047 & 78.3 & 290 & 21.7 & \multirow{2}{*}{$<0.001$} \\
\hline Female & 1120 & 1051 & 93.8 & 69 & 6.2 & \\
\hline \multicolumn{7}{|l|}{ Age (years) } \\
\hline $10-$ & 34 & 33 & 97.1 & 1 & 2.9 & \multirow{5}{*}{$<0.001$} \\
\hline $12-$ & 539 & 500 & 92.8 & 39 & 7.2 & \\
\hline $14-$ & 889 & 756 & 85.0 & 133 & 15.0 & \\
\hline $16-$ & 784 & 660 & 84.2 & 124 & 15.8 & \\
\hline $18^{+}$ & 93 & 59 & 63.4 & 34 & 36.6 & \\
\hline \multicolumn{7}{|l|}{ Nationality } \\
\hline Local & 912 & 733 & 80.4 & 179 & 19.6 & \multirow{2}{*}{$<0.001$} \\
\hline Non-local & 1545 & 1365 & 88.3 & 180 & 11.7 & \\
\hline \multicolumn{7}{|l|}{ Mother's education } \\
\hline Illiterate & 116 & 98 & 84.5 & 18 & 15.5 & \multirow{5}{*}{0.017} \\
\hline Primary & 99 & 84 & 84.8 & 15 & 15.2 & \\
\hline Preparatory & 103 & 76 & 73.8 & 27 & 26.2 & \\
\hline Secondary & 451 & 387 & 85.8 & 64 & 14.2 & \\
\hline University & 1657 & 1427 & 86.1 & 230 & 13.9 & \\
\hline \multicolumn{7}{|l|}{ Father's education } \\
\hline Illiterate & 79 & 50 & 63.3 & 29 & 36.7 & \multirow{5}{*}{$<0.001$} \\
\hline Primary & 136 & 104 & 76.5 & 32 & 23.5 & \\
\hline Preparatory & 51 & 44 & 86.3 & 7 & 13.7 & \\
\hline Secondary & 307 & 258 & 84.0 & 49 & 16.0 & \\
\hline University & 1857 & 1618 & 87.1 & 239 & 12.9 & \\
\hline \multicolumn{7}{|l|}{ Family history of smoking } \\
\hline No & 1742 & 1542 & 88.5 & 200 & 11.5 & \multirow{2}{*}{$<0.001$} \\
\hline Yes & 715 & 557 & 77.9 & 158 & 22.1 & \\
\hline \multicolumn{2}{|l|}{ Knowledge and attitudes towards tobacco } & \multicolumn{2}{|c|}{ Mean (SD) } & \multicolumn{2}{|c|}{ Mean (SD) } & \\
\hline Knowledge score & 2346 & \multicolumn{2}{|c|}{$5.58(1.79)$} & & & $0.004^{\mathrm{b}}$ \\
\hline Attitude score & 2340 & & .29) & & & $0.004^{\mathrm{b}}$ \\
\hline
\end{tabular}

${ }^{a}$ Chi-squared test; ${ }^{b}$-test.

$S D=$ standard deviation .

\section{Factors associated with tobacco use}

Regarding sociodemographic characteristics, Table 2 shows that $23.3 \%$ of smokers were attending government schools and only $12.5 \%$ private schools, and this difference was statistically significant $(P<0.001)$. Males had a significantly higher rate of tobacco use than females ( $21.7 \%$ versus
6.2\% $)(P<0.001)$. In addition, locals (UAE nationals) were more likely to be tobacco users than non-locals $(19.6 \%$ versus $11.7 \%)(P<0.001)$. Concerning parents' education, 
students of illiterate or primary-educated parents had the highest rates of tobacco use $(15.5 \%$ and $15.2 \%$ for mothers and $36.7 \%$ and $23.5 \%$ for fathers respectively), while the lowest rates of use were observed among those of university or higher-educated parents (13.9\% and $12.9 \%$ respectively for mother and fathers); these differences were statistically significant $(P=0.017$ for mothers and $P<0.001$ for fathers). Students with a family history of smoking were more likely to be tobacco users compared with those without such history $(22.1 \%$ versus $11.5 \%)(P<0.001)$.

Stepwise logistic regression analysis of the factors affecting tobacco users (Table 3) delineated 7 predictors for tobacco use: age, sex, nationality, school type, school grade, family history and knowledge about hazards of tobacco. Higher age, male sex, family history of smoking, being in secondary grade of education (10-12 years), being a UAE local and being in a government school were all significantly associated with a higher risk of tobacco use compared with those who were of younger age, female, with no family history of smoking, in preparatory grade of education (7-9 years), non-UAE nationality or being in a private school $(\mathrm{ORs}=1.31$, $4.15,1.65,1.50,1.75$ and 1.59 respectively). Furthermore, a higher score on knowledge about tobacco and its effects was associated with a lower risk of tobacco use.

\section{Effect of intervention on knowledge and attitudes}

Concerning the effect of the intervention programme on the knowledge and attitude of students towards tobacco use, Table 4 shows that there was an increase in the percentage of students with a good level of knowledge from $34.1 \%$ before to $51.9 \%$ after the intervention programme. The mean knowledge score increased significantly from 5.49 (SD 1.81) before to 6.14 (SD 1.31) after the intervention $(P<0.001)$. The same pattern was observed concerning attitudes; there was an increase in the rate of positive attitudes from $34.5 \%$ before to $48.7 \%$ after the intervention programme. Mean scores also increased from 28.31 (SD 4.04) to 29.23 (SD 3.99) $(P<0.001)$.

\section{Discussion}

The prevalence of tobacco use among adolescents is a valuable indicator for the prediction of future harm caused by tobacco and is therefore important for health-related policy-makers and programme planners in any country (16). Prevalence and trends in smoking vary from country to country, often dependent on the level of monitoring of tobacco use behaviour. The results of the present study revealed that the overall prevalence of current tobacco use in school students in the UAE was 14.6\%; this was lower than previous surveys

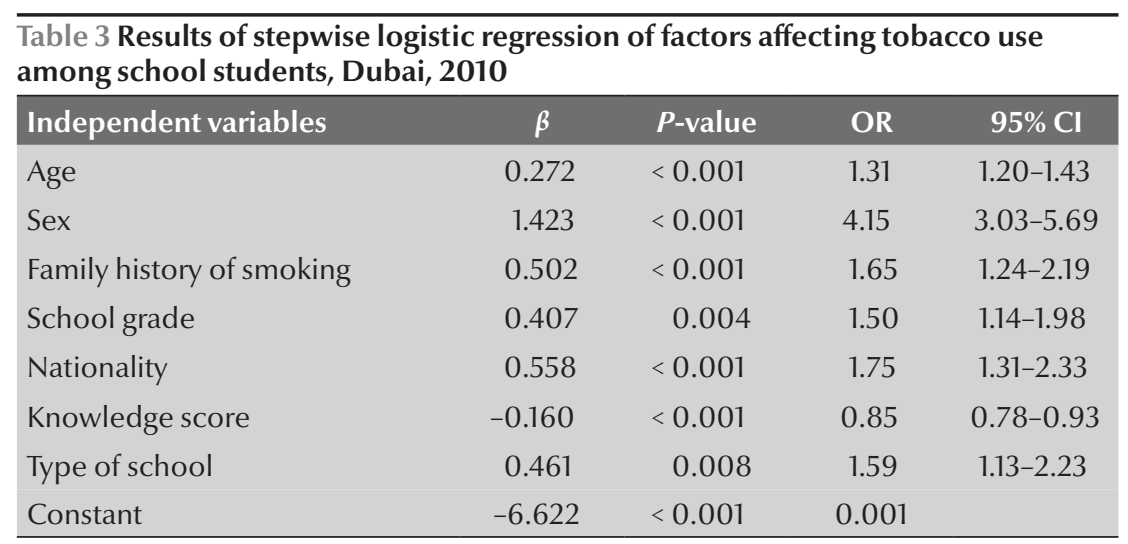

$O R=$ odds ratio $; C I=$ confidence interval $; \beta=$ regression coefficient. from Yemen in 2003 (17), Saudi Arabia in 2007 (18) and Jordan in 2007 (19) (prevalences of any current tobacco use were $19.3 \%, 17.3 \%$ and $21.8 \%$ respectively). Furthermore, a higher prevalence of tobacco use $(24.5 \%)$ was reported in a Syria study in 2010 (20).

The present study established that smoking cigaretteswasthe predominant form of tobacco use among the current tobacco users (11.2\%), and this was higher than the prevalence of current cigarette smoking reported in Oman in $2006(4.5 \%)$ (21) and previously in the Dubai Emirate in 2010 (9.8\%) (8). Results from Tehran, Islamic Republic of Iran in 2003 (22) reported that the prevalence of cigarette smoking was $28.2 \%$, which was much higher than in the present study.

The prevalence of waterpipe smoking in our study was $2.2 \%$, which was lower than the Saudi Arabian study (8.7\%) (18) and far lower than a study in Lebanon (25.6\%) (23).

\section{Self-reported reason for tobacco use}

The present study showed that $29.4 \%$ of students reported that trying out the experience was the main reason for tobacco use. This finding was similar to a Saudi Arabian study (24). Young students experience feelings of uncertainty about their self-image and consider themselves more or less dependent on the opinion and judgement of their peers. Meeting these expectations of one's peer group is essential to prevent loss of friends, becoming a loner and eventually losing one's social identity (25). Another reason for tobacco use among students in the present study was to relieve stress. This result was in accordance with a study in the United States of America (USA) (26).

\section{Associated factors of tobacco use}

Tobacco use was more common in the government than private schools, which can be explained by better educational 


\begin{tabular}{|c|c|c|c|c|c|}
\hline \multirow[t]{2}{*}{ Variable } & \multicolumn{2}{|c|}{ Before intervention } & \multicolumn{2}{|c|}{ After intervention } & \multirow[t]{2}{*}{$P$-value ${ }^{c}$} \\
\hline & No. & $\%$ & No. & $\%$ & \\
\hline \multicolumn{6}{|l|}{ Knowledge level } \\
\hline Poor & 821 & 35.0 & 404 & 17.2 & \\
\hline Fair & 724 & 30.9 & 725 & 30.9 & \\
\hline Good & 801 & 34.1 & 1217 & 51.9 & \\
\hline Total mean (SD) score & \multicolumn{2}{|c|}{$5.49(1.81)$} & \multicolumn{2}{|c|}{$6.14(1.31)^{\mathrm{a}}$} & $<0.001$ \\
\hline \multicolumn{6}{|l|}{ Attitude level } \\
\hline Negative & 966 & 41.3 & 714 & 30.5 & \\
\hline Neutral & 566 & 24.2 & 486 & 20.8 & \\
\hline Positive & 808 & 34.5 & 1140 & 48.7 & \\
\hline Total mean (SD) score & \multicolumn{2}{|c|}{$28.31(4.04)$} & \multicolumn{2}{|c|}{$29.23(3.99)^{\mathrm{b}}$} & $<0.001$ \\
\hline
\end{tabular}

${ }^{a}$ Data missing for 111 students; ${ }^{b}$ Data missing for 117 students; ${ }^{c} t$-test. $S D=$ standard deviation.

activities or a close monitoring system and restrictions on the use of tobacco in private schools more than government schools, and may also be due to social class differences between the school populations.

Tobacco prevalence increased as age increased. This result is consistent with a previous study in Taiwan (27) but inconsistent with an Iranian study (28), in which the highest prevalence of tobacco use was reported among younger students compared with the older students. Exposure to tobacco advertising in the latter study was a strong correlate of tobacco use among younger students.

Males are typically at a much higher risk for tobacco use than are females and this was supported by the present study and others in the region, for example from the Syrian Arab Republic (29). This can be explained by smoking being a more acceptable social behaviour for males and also due to possible underreporting by female students.

Higher stage of education tends to be associated with a higher likelihood of tobacco use. The present study agreed with this, as students in secondary grade classes were using tobacco more than those in the preparatory grades. This was also supported by the National Youth
Tobacco survey in the USA in 2004, which found that $28 \%$ of high-school and $12 \%$ of middle-school students reported current tobacco use (30).

The present study found an inverse relationship between students' use of tobacco and parents' education. This is in agreement with other studies, for example in the USA (31). Highly educated parents are more knowledgeable about the health consequences of tobacco use and they can prevent their children from taking up tobacco.

The present study highlights the important effects of parents' and siblings' tobacco behaviour on current tobacco use by students. Tobacco use by parents and friends, knowledge about the harmful effects of tobacco, smoking, environmental smoke and attitudes to tobacco use by others were strongly associated with student tobacco use. Social learning theory suggests that learning (of an attitude or habit) occurs through observation, i.e. the parent's behaviour is normally copied by the children (32). This is consistent with the present study. Parents' tobacco use contributes to the onset of daily tobacco use in their teenagers even if parents practise good family management, hold norms against teen tobacco use and do not involve their children in their own tobacco use
(33). We showed that students who did not use tobacco had better knowledge and attitudes toward tobacco use and its hazards than did tobacco users, and vice versa. These results are consistent with other studies, in south Australia (34) and Turkey (35).

\section{Impact of intervention programme on knowledge and attitudes}

Researchers have indicated that tobacco prevention programmes have positive influences on students' tobacco use and prevention of addiction. Therefore, in order to decrease the use of tobacco among teenagers, tobacco education programmes are suggested to cultivate students' positive perceptions and refusal skills (36). Youth are easily influenced by their favourite idols who smoke, and a positive correlation between a popular idol's smoking habits and adolescent smoking has been found (37). A Taiwanese study showed that students' post-intervention scores on the knowledge of tobacco hazard, antismoking attitudes and ability to refuse smoking were significantly higher than those in the pre-intervention period. This indicated that both the delivery of tobacco prevention brochures and the implementation of tobacco prevention programmes to reinforce teenager's 
knowledge of tobacco hazards and attitudes against smoking were effective in decreasing youth smoking (36). Those findings are in accordance with the present study and a study in India (38).

This study has the same limitations inherent in any cross-sectional school survey, where data collection is limited to a single time point. Tobacco use status was assessed by self-reporting and therefore some students may have under-reported their tobacco use. Moreover, the existing taboos about tobacco use, especially among female students in this region, might also lead to underreporting. The estimated prevalence in the study may therefore be slightly lower than the actual prevalence.

\section{Conclusion and Recommendations}

Tobacco use constitutes a real public health problem among this group of adolescents in the UAE. About 15\% were self-reported current users of tobacco, and cigarette smoking was the most prevalent type. The most common reasons for tobacco use were trying out the experience, to relieve stress and peers' smoking. About one-third or more of the students demonstrated poor knowledge or negative (favourable) attitudes towards smoking. There was a significant improvement in knowledge and attitude scores after the 1-day intervention programme.

It is recommended that health education programmes to raise awareness about the hazards of smoking for teenagers and adolescents are continued in schools and that parents and concerned staff are actively engaged in the process, with an emphasis on encouraging youth support groups working against tobacco use among youth.

Competing interests: None declared.

\section{References}

1. WHO Report on the Global Tobacco Epidemic, 2008: the MPOWER package. Geneva: World Health Organization; 2008 http://whqlibdoc.who.int/publications/2008/9789241596282_eng.pdf?ua=1, accessed 5 August 2014).

2. Santrock JW. Adolescence. Boston: McGraw-Hill; 2005.

3. Nelson DE, Mowery P, Asman K, Pederson LL, O'Malley PM, Malarcher A, et al. Long-term trends in adolescent and young adult smoking in the United States: metapatterns and implications. Am J Public Health. 2008 May;98(5):905-15. PMID:18382001

4. Townsend L, Flisher AJ, Gilreath T. A systematic review of tobacco use among sub-Saharan African youth. J Subst Use. 2006; 11:245-69.

5. Ausems M, Mesters I, van Breukelen G, De Vries H. Smoking among Dutch elementary schoolchildren: gender-specific predictors. Health Educ Res. 2009 Oct;24(5):818-28. PMID:19351704

6. Al-Damegh SA, Saleh MA, Al-Alfi MA, Al-Hoqail IA. Cigarette smoking behavior among male secondary school students in the Central region of Saudi Arabia. Saudi Med J. 2004 Feb;25(2):215-9. PMID:14968222

7. Global Youth Tobacco Survey. Country fact sheets: Egypt. Geneva: World Health Organization; 2005 (http://www. emro.who.int/images/stories/tfi/documents/GYTS_FS_EGY R2.pdf?ua=1, accessed 5 August 2014).

8. Fikri M, Al-Matroushi M. Global Youth Tobacco Survey. UAE report. Abu Dhabi: Central Health Education Department, Ministry of Health; 2005.

9. Golbasi Z, Kaya D, Cetindag A, Capik E, Aydogan S. Smoking prevalence and associated attitudes among high school students in Turkey. Asian Pac J Cancer Prev. 2011;12(5):1313-6. PMID:21875288

10. Lin YS, Wu DM, Lai HR, Shi ZP, Chu NF. Influence of knowledge and attitudes on smoking habits among young military conscripts in Taiwan. J Chin Med Assoc. 2010 Aug;73(8):411-8. PMID:20728852

11. WHO Framework Convention on Tobacco Control. Geneva: World Health Organization; 2003 (www.who.int/tobacco/ framework/WHO_FCTC_english.pdf, accessed 5 August 2014).
12. The UAE law [Internet] (http://theuaelaw.com/vb/showthread.php?t $=670$, accessed 5 August 2014).

13. Global Youth Tobacco Survey (GYTS) core questionnaire with optional questions. Version 1.0 July 2012. Atlanta (GA): Centers for Disease Control and Prevention; 2012 (http://nccd.cdc. gov/GTSSData/Ancillary/DownloadAttachment.aspx?!D=33, access 25 August 2012).

14. Martini S, Sulistyowati M. The determinants of smoking behavior among teenagers in East Java Province, Indonesia. Health, Nutrition and Population (HNP) Discussion Paper. Washington (DC): World Bank; 2005 (Economics of Tobacco Control Paper No. 32) (http://siteresources.worldbank. org/HEALTHNUTRITIONANDPOPULATION/Resources/281627-1095698140167/IndonesiaYouthSmokingFinal. pdf, accessed 5 August 2014).

15. Dumluck S. Prevalence of smoking and factors influenced to smoking behavior among secondary school and vocational school student in Phuket Province, Thailand, 2008 [MPH thesis]. Bangkok: College of Public Health Sciences, Chulalongkorn University; 2007.

16. Thun MJ. Luiza da Costa e Silva V. Introduction and overview of global tobacco surveillance. Tobacco control country profiles. 2nd ed. Atlanta (GA): American Cancer Society; 2003. pp. 7-12.

17. Bahaj AA, Baamer AA, Bin Briek AS. Prevalence of tobacco use among young students in Yemen. JBMS. 2010;22(1):5-8.

18. Al-Bedah AM, Qureshi NA, Al-Guhaimani HI, Basahi JA. The Global Youth Tobacco Survey-2007. Comparison with the Global Youth Tobacco Survey 2001-2002 in Saudi Arabia. Saudi Med J. 2010 Sep;31(9):1036-43. PMID:20844818

19. Global Youth Tobacco Survey, Jordan, 2007. Amman: Ministry of Public Health; 2007.

20. Global Youth Tobacco Survey, Syria, 2010. Damascus: Ministry of Public Health; 2010.

21. Jaffer YA, Afifi M, Al Ajmi F, Alouhaishi K. Knowledge, attitudes and practices of secondary-school pupils in Oman: I. healthcompromising behaviours. East Mediterr Health J. 2006 JanMar;12(1-2):35-49. PMID:17037220

22. Heydari GR, Milani HS, Hosseini M, Masjedi MR. Attitude of high school students of Tehran towards tobacco use. Tanaffos. 2004;3(11):29-35. 
23. Tamim H, Al-Sahab B, Akkary G, Ghanem M, Tamim N, El Roueiheb Z, et al. Cigarette and nargileh smoking practices among school students in Beirut, Lebanon. Am J Health Behav. 2007 Jan-Feb;31(1):56-63. PMID:17181462

24. Al-Haqwi Al, Tamim H, Asery A. Knowledge, attitude and practice of tobacco smoking by medical students in Riyadh, Saud Arabia. Ann Thorac Med. 2010 Jul;5(3):145-8. PMID:20835308

25. Ali NH, Al-Hussaini AS, Al-Haid NS. Factors associated with smoking habits among Kuwaiti students in the age group 9-18 years. Kuwait Med J. 2007;39(4):330-4.

26. Kirby JB. The influence of parental separation on smoking initiation in adolescents. J Health Soc Behav. 2002 Mar;43(1):56-71. PMID:11949197

27. Wen CP, Tevy DT, Chang T, Hsu CC, Tsai SP. Smoking behavior in Taiwan. Tob Control. 2005;14:i51--i55. doi:10.1136/ tc.2004.008011

28. Ramezankhani A, Zaboli FS, Zarghi A, Masjedi MR, Heydari GR. Smoking habits of adolescent students in Tehran. Tanaffos. 2010;9(2):33-42.

29. Maziak W, Mzayek F. Characterization of the smoking habit among high school students in Syria. Eur J Epidemiol. 2000;16(12):1169-76. PMID:11484808

30. Bloch AB, Mowery PD, Carabalo RS; Centers for Disease Control and Prevention (CDC). Tobacco use, access, and exposure to tobacco in media among middle and high school studentsUnited States, 2004. MMWR Morb Mortal Wkly Rep. 2005 Apr 1;54(12):297-301. PMID:15800473

31. Orlando M, Tucker JS, Ellickson PL, Klein DJ. Developmental trajectories of cigarette smoking and their correlates from early adolescence to young adulthood. J Consult Clin Psychol. 2004 Jun;72(3):400-10. PMID:15279524

32. Wen X, Chen W, Muscat JE, Qian Z, Lu C, Zhang C, et al. Modifiable family and school environmental factors associated with smoking status among adolescents in Guangzhou, China. Prev Med. 2007 Aug-Sep;45(2-3):189-97. PMID:17433427

33. Hill KG, Hawkins JD, Catalano RF, Abbott RD, Guo J. Family influences on the risk of daily smoking initiation. J Adolesc Health. 2005 Sep;37(3):202-10. PMID:16109339

34. Dollman J, Lewis F. Trends in health attitudes and self-perceptions among school-age South Australians between 1985 and 2004. Aust N Z J Public Health. 2007 Oct;31(5):407-13. PMID:17931285

35. Golbasi Z, Kaya D, Cetindag A, Capik E, Aydogan S. Smoking prevalence and associated attitudes among high school students in Turkey. Asian Pac J Cancer Prev. 2011;12(5):1313-6. PMID:21875288

36. Tsai WC, Kung PT, Hu HY, Sung C, Lin DJ, Hsieh CL, et al. Effects of a tobacco prevention education program on adolescents knowledge of and attitudes toward smoking. Taichung, Taiwan: Asia University (http://www.asia.edu.tw/Main_pages/academics/teacher_research/pk_kung/14.pdf, accessed 5 August 2014).

37. Lee JM. The study on the responses to cigarette advertisement among the elementary, junior high, and senior high school students in Taipei. Health Promotion and Health Education Journal. 1998;18:13-8.

38. Perry $\mathrm{CL}$, Stigler MH, Arora M, Reddy KS. Preventing tobacco use among young people in India: project MYTRI. Am J Public Health. 2009 May;99(5):899-906. PMID:19299670 